\title{
The effect of modification of binders on technological and operational properties of composite construction materials
}

\author{
Lyubov Zakrevskaya ${ }^{1, *}$, Igor Handelsman ${ }^{1}$, and Galina Provatorova ${ }^{1}$ \\ ${ }^{1}$ Vladimir state university named after Alexander and Nikolay Stoletovs, 600000, Gorky 87 Vladimir, \\ Russia
}

\begin{abstract}
The object of the study includes modified road bitumen and geotextile materials, for the synthesis of which recycled PET and CNT were used. The production of new materials is caused by the need to improve their technical characteristics, which, in the end, should have a positive impact on the properties of composites based on them. The main method of research is an experiment. During the experiment, a grid of compositions of new materials and laboratory technology for their production were developed, their basic properties were studied. According to the results of the study of the basic properties of new materials there is an improvement of their basic properties up to $10 \%$ compared to the original ones.
\end{abstract}

\section{Introduction}

At present a major challenge facing builders is the efficient use of material resources to reduce costs. In this context application of secondary resources, especially in areas with a shortage of traditional construction materials is currently important. Waste polyethylene terephthalate results from manufacturing processing of raw materials into products. Every year Russia produces about 300-400 thousand tons of polyethylene terephthalate waste. To date, the cost of PET waste disposal remains quite high [10,21].

A common method of disposal of household waste plastics is incineration. Higher calorific value of $1 \mathrm{t}$ of plastic packaging waste is equivalent to the specific higher calorific value of $0.5 \mathrm{t}$ of oil $(11,350 \mathrm{~kJ} / \mathrm{kg})$. In the estimation of various experts up to $40 \%$ of plastic waste is burned.

About one third of secondary PET is used to manufacture fibers for carpets, synthetic fibers, clothes and geotextiles.

Modernization of construction provides longer service life of materials, the extension of the construction seasons, cost reduction and high performance of buildings throughout the entire service life [22, 24].

Another promising direction is the modification of organic binders.

\footnotetext{
*Corresponding author: 1vzak@mail.ru
} 
Fibers made from recycled PET are used in geosynthetic materials, which have qualitatively new properties that are different from traditional materials in terms of high strength, durability, chemical resistance, resistance to temperature extremes, corrosive effects of the environment $[11,23]$.

The use of geosynthetics provides high level of design solutions, construction technology, conservation of natural resources, and compliance with environmental requirements. These materials are used to protect viaducts, install retaining walls, strengthen slopes and foundations of road embankments, and reinforce foundations and bituminous concrete surface. The lifetime of objects constructed with the use of these materials is $50-100$ years [27].

Geosynthetics is highly effective for protection of pipelines and excavations from wind and water erosion. Application of such materials is effective for slope stability, reduces or even eliminates erosion. The use of this technology contributes to a significant increase of lifetime of engineering structures and eliminates the need for continuous reconstruction.

Thus, PET waste based materials allow for solving the following construction problems:

- surface water drainage;

- protection of dangerous sites of roads in the mountains;

- separation and filtering of structural layers;

- strengthening of weak bases;

- strengthening and increase of service life of roadway surfacing;

- strengthening ballast and under-ballast layers in railway tracks;

- protection of pipeline crowning;

- construction of site structures;

- construction of temporary roads;

- waterproofing of structures.

Our country has got considerable experience in the modification of both inorganic and organic binders. High performance of bituminous concrete is a dominant factor to ensure reliability of roads.

The relevance of modification of the organic binder is associated with increasing mechanical loads on asphalt of road surface. Binder behaviour is significantly affected by the temperature [25].

In this study an attempt was made to improve operational and technological properties of bitumen by their modification with polyethylene terephthalate (PET) and carbon nanotubes (CNT).

One of the directions of organic binders modification is associated with the introduction of carbon nanoscale structures into bitumen. This type of modification is fairly costly at all stages of the process, from the CNT production to introduction of CNT in the composition of the bitumen. It is known that introduction of CNT in the composition of the asphalt concrete increases a range of its operating abilities by $10 \%$ to $30 \%[9,12]$.

Modification of inorganic binders with nanostructures of synthetic and natural origin improves their strength characteristics, which in turn makes it possible to improve the quality of engineering materials $[12,13,26]$.

Comparative analysis of modified and unmodified bitumens is shown in table 1 . 
Table 1. Characteristics of the bitumen BND 60/90 in modified with PET and unmodified.

\begin{tabular}{|c|c|c|c|c|c|c|c|}
\hline \multirow[t]{2}{*}{ № } & \multirow[t]{2}{*}{$\begin{array}{l}\text { Name of the } \\
\text { indicator }\end{array}$} & \multirow[t]{2}{*}{$\begin{array}{c}\text { Amount of } \\
\text { modifier, } \\
\% \text { mass }\end{array}$} & \multirow[t]{2}{*}{ Unit } & \multirow{2}{*}{\multicolumn{2}{|c|}{$\begin{array}{c}\text { Bitumen BND } \\
\text { 60/90 modified } \\
\text { PET }\end{array}$}} & \multirow{2}{*}{\multicolumn{2}{|c|}{$\begin{array}{l}\text { Bitumen BND } \\
60 / 90 \text { unmodified } \\
\text { (base sample) }\end{array}$}} \\
\hline & & & & & & & \\
\hline \multirow{3}{*}{1} & \multirow{3}{*}{$\begin{array}{l}\text { The depth of } \\
\text { penetration of } \\
\text { the needle } \\
\text { At } 25^{\circ} \mathrm{C} / \\
\text { At } 0^{\circ} \mathrm{C}\end{array}$} & 0.5 & \multirow{3}{*}{$0.1 \mathrm{~mm}$} & 83 & 22 & \multirow{3}{*}{83} & \multirow{3}{*}{22} \\
\hline & & 0.75 & & 84 & 23 & & \\
\hline & & 1.0 & & 86 & 23 & & \\
\hline \multirow{3}{*}{2} & \multirow{3}{*}{$\begin{array}{l}\text { Softening } \\
\text { temperature } \\
\text { by the ring } \\
\text { and ball, } \\
\text { minimum }\end{array}$} & 0.5 & \multirow{3}{*}{${ }^{\circ} \mathrm{C}$} & 50 & 50 & \multirow{3}{*}{\multicolumn{2}{|c|}{48}} \\
\hline & & 0.75 & & 52 & 52 & & \\
\hline & & 1.0 & & 53 & 53 & & \\
\hline \multirow{3}{*}{3} & \multirow{3}{*}{$\begin{array}{c}\text { Extensibility, } \\
\text { min } \\
\text { At } 25^{\circ} \mathrm{C} / \\
\text { At } 0^{\circ} \mathrm{C}\end{array}$} & 0.5 & \multirow{3}{*}{$\mathrm{cm}$} & 101 & 3.5 & \multirow{3}{*}{97} & \multirow{3}{*}{3.5} \\
\hline & & 0.75 & & 102 & 3.7 & & \\
\hline & & 1.0 & & 107 & 3.7 & & \\
\hline
\end{tabular}

\section{Methods}

The goal of this study is to develop new makeup of modified bitumen due to the introduction of the organic binder of CNT and recycled PET, as well as technologies for the introduction of complex modifiers.

The surface defects of asphalt concrete that may occur when roads are used are dependent on the correlation of rheological and physical and mechanical properties of the binder. According to I. A. Rybiev [1] there is a direct correlation between physicalmechanical properties of construction materials and the binder, forming its structure.

Polimeric bitumen binder is a dispersion system consisting of hydrocarbons, resins, and asphaltenes [2]. The structure of asphaltenes [3] is similar to the structure of graphite layered formation which is strictly oriented in parallel.

Improvement of properties of bitumen with modern modifiers (polymer additives, nanomodifiers, etc.) is discussed in numerous papers $[4,5,14,18]$.

Diagram, Fig. 1, presents the classification of modifiers of bitumens.

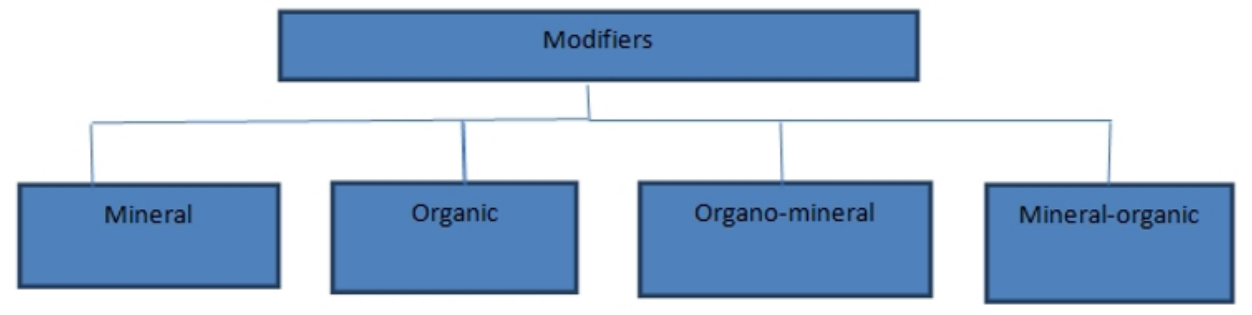

Fig. 1. Classification of bitumen modifiers.

This paper presents a complex polymer modification. The effectiveness of polymer modification depends on the resulting structure [5]. 
In turn, the use of nanotechnology $[6,13]$ allows for solving a lot of problems due to the control over formation of a composite structure.

To improve the strength characteristics various carbon nanostructures are successfully used [8]. They have a reinforcing effect, which depends on the method of their introduction into the composition and uniformity of its distribution in volume.

CNT is a hollow nanofiber [8], which is a threadlike particle of carbon atoms.

In this study, we used carbon nanotubes obtained by gas phase deposition in the laboratory of Vladimir State University.

In most cases [8], the agglomeration of CNT results in the weakening of their influence on the strength characteristics of construction composites.

In the research the mechanical method of dispersion with ultrasound in the medium of organic solvent was applied, since according to $[9,15,16]$, in this case, molecular aggregates (nanocolloid) were formed.

Our objective was to determine the optimal concentration of CNT for maximum strength achieved before the point of formation of agglomerates [11], which worsen the quality indicators.

Table 2 presents the compositions scale of the modified binder.

Table 2. The compositions of the modified binder.

\begin{tabular}{|c|c|c|c|c|}
\hline \multirow[b]{2}{*}{ Sample } & \multirow[b]{2}{*}{ № of a sample } & \multicolumn{3}{|c|}{ component percentage } \\
\hline & & $\begin{array}{c}\text { Bitumen BND } \\
60 / 90\end{array}$ & $\begin{array}{l}\text { PET, } \% \text { mass in } \\
\text { the organic } \\
\text { solvent additive }\end{array}$ & $\begin{array}{l}\text { CNT, \% mass in } \\
\text { the organic } \\
\text { solvent additive }\end{array}$ \\
\hline Basic & Without marking & 100 & - & - \\
\hline \multirow{6}{*}{ Modified } & 1 & 95 & 0.5 & 4.5 \\
\hline & 2 & 95.5 & 0.75 & 3.75 \\
\hline & 3 & 95.5 & 1.0 & 3.5 \\
\hline & 4 & 95.5 & 1.5 & 3.0 \\
\hline & 5 & 95.5 & 2.5 & 2.0 \\
\hline & 6 & 94 & 5.0 & 1.0 \\
\hline
\end{tabular}

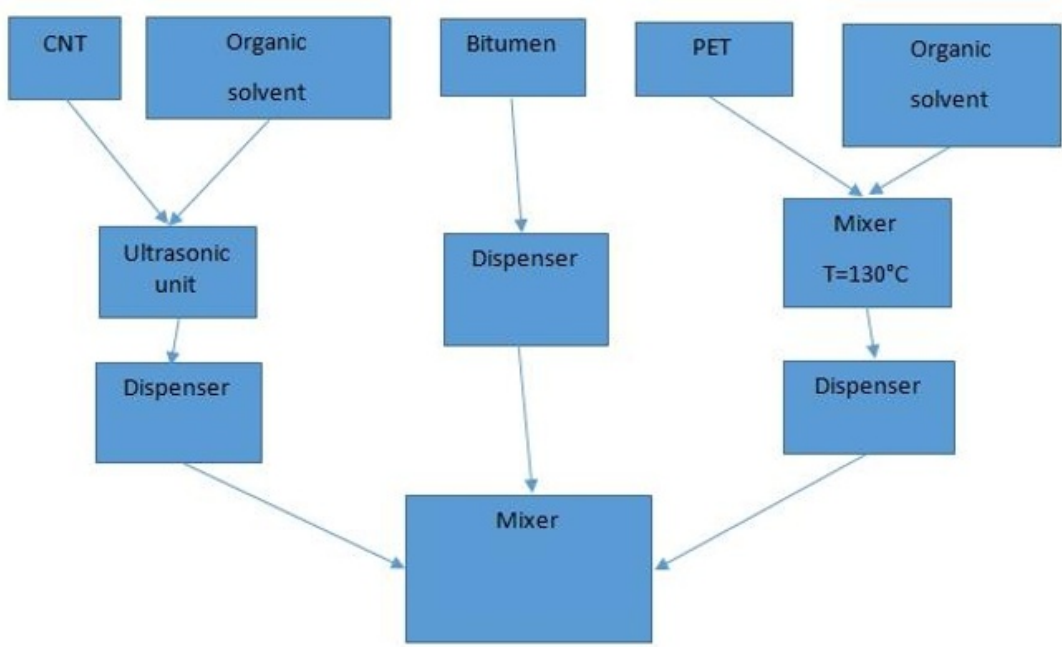

Fig. 2. A flowchart of the laboratory process for producing modified binder. 
Process and instrumentation diagram of the preparation of nano-modified bitumen in laboratory conditions included the following processes.

1. Preparation of a suspension by ultrasonic dispersion of carbon nanotubes in the organic solvent medium at a temperature of $70^{\circ} \mathrm{C}$ for 2 minutes.

2. Preparation of the PET solution in an organic solvent medium at a temperature of $130^{\circ} \mathrm{C}$ until homogeneous.

3. Simultaneous introduction of both measured components in bitumen at a temperature of $130^{\circ} \mathrm{C}$ with thorough stirring.

Figure 2 shows a flowchart of the laboratory process for producing modified binder.

The study was carried out with bitumen BND 60/90 as the most common for road construction in climatic zone II.

\section{Results and Discussion}

Cointroduction of PET and CNT made it possible to obtain material with the indicators presented in table 3 due to the synergetic modifying effect.

Table 3. Properties of modified bitumen.

\begin{tabular}{|c|c|c|c|}
\hline Sample & $\begin{array}{c}\text { Penetration at } \\
\text { temperature } \\
25 / 0^{\circ} \mathrm{C}, 0.1 \mathrm{~mm}\end{array}$ & $\begin{array}{c}\text { Elasticity at a } \\
\text { temperature } \\
25 / 0{ }^{\circ} \mathrm{C}, \mathbf{c m}\end{array}$ & $\begin{array}{c}\text { Ring and ball } \\
\text { softening point, } \\
{ }^{\circ} \mathrm{C}\end{array}$ \\
\hline $\begin{array}{c}\text { Without } \\
\text { marking }\end{array}$ & $83 / 22$ & $97 / 3.5$ & 48 \\
\hline 1 & $84 / 23$ & $101 / 3.5$ & 50 \\
\hline 2 & $86 / 23$ & $102 / 3.7$ & 52 \\
\hline 3 & $86.5 / 23$ & $107 / 3.7$ & 53 \\
\hline 4 & $86 / 23$ & $108 / 3.7$ & 53 \\
\hline 5 & $85 / 23$ & 1073.7 & 53 \\
\hline 6 & $84 / 23$ & $107 / 3.69$ & 52.5 \\
\hline
\end{tabular}

The test results for modified bitumen are illustrated in figures 3-5.

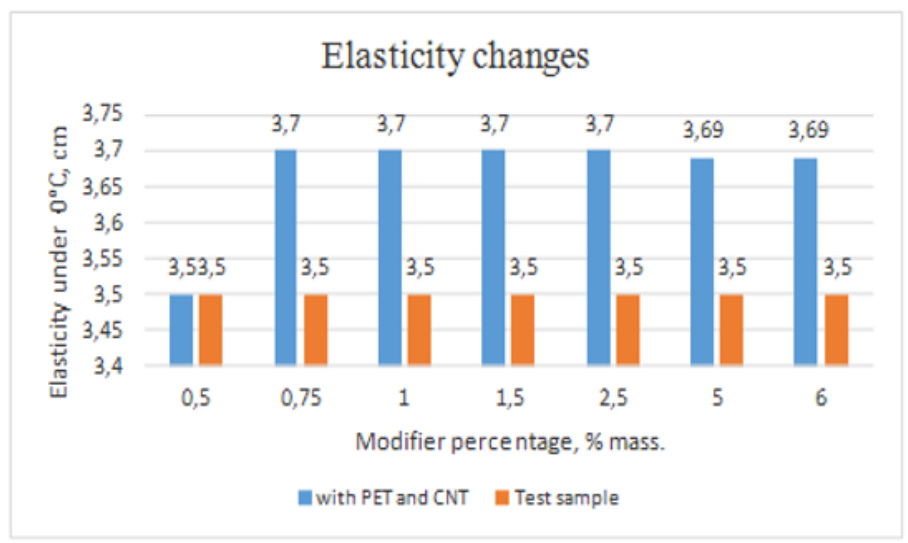

Fig. 3. Diagram of changes in elasticity of the bitumen BND $60 / 90$ at $0^{\circ} \mathrm{C}$. 


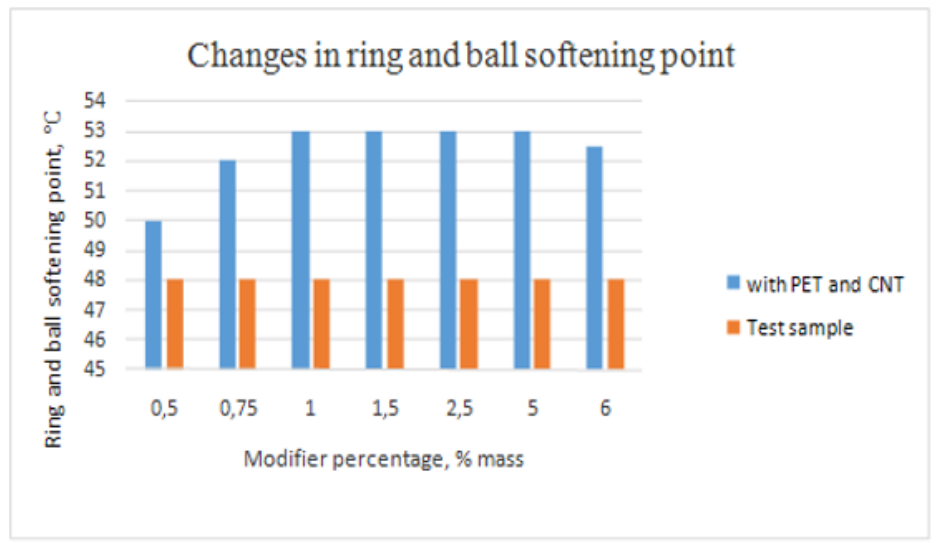

Fig. 4. Diagram of changes in ring and ball softening point of the bitumen BND 60/90.

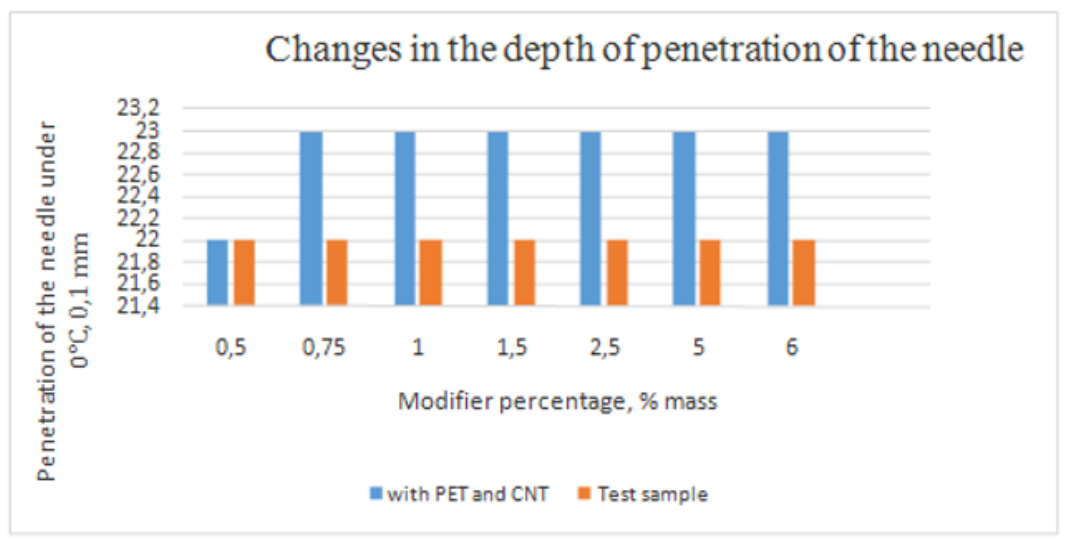

Fig. 5. Diagram of changes in the depth of the needle penetration into the bitumen BND $60 / 90$ at $0^{\circ} \mathrm{C}$.

Various studies show that the optimum amount of PET introduced into the bitumen is 4$6 \%[13,20]$, however introduction of such amount in some cases may cause aggregating in the bulk of bitumen [29]. To eliminate or reduce the risk of such phenomena it was proposed to use a complex modifier of PET $+\mathrm{CNT}$.

Further increase in the concentration of the introduced modifier to $2.5 \%$ did not evidence marked improvement of the properties of the binder, but increasing the concentration to $5 \%$ or higher revealed a trend to the reduction of previously obtained values.

Non-woven permeable geotextile material with improved operational performance based on recycled PET was obtained due to the introduction of carbon nanotubes in its composition. The technology of CNT introduction in the recycled PET is similar to that used in bitumen modification. Table 4 presents the results of the study of the new material and its comparative characteristics as against geotextile without CNT. 
Table 4. Comparative properties of geotextiles on the basis of recycled PET with the comparable modified CNT.

\begin{tabular}{|c|c|c|}
\hline \multirow{2}{*}{$\begin{array}{c}\text { Physical-mechanical } \\
\text { properties of the material }\end{array}$} & \multicolumn{2}{|c|}{ Numerical values } \\
\cline { 2 - 3 } & PET-based material & $\begin{array}{c}\text { PET-based material modified } \\
\text { with CNT }\end{array}$ \\
\hline Density, $\mathrm{kg} / \mathrm{m} 3$ & $400-800$ & $500-880$ \\
\hline Compression strength, MPa & $40-65$ & $68-72$ \\
\hline Water absorption, \% vol. & 0.6 & 0.6 \\
\hline Frost resistance, cycle & 50 & 65 \\
\hline
\end{tabular}

The table shows that in some cases properties of geotextile material are improved by 8 $10 \%$ due to modifications with CNT.

\section{Conclusions}

According to the study:

1. Possibility to use recycled PET and CNT as modifiers of bitumen has been proved.

2. Technology of the dispersion of PET, functionalized CNT, in the mass of bitumen has been developed.

The obtained experimental data allows for the following conclusions:

1. Coadministration of polymer modifier and CNT into the composition of road bitumen allowed us to obtain organic binder with improved performance characteristics and a wide range of applications [12, 30].

2. The developed composition and technology contribute to saving of natural raw materials due to recycling of industrial waste, improvement of the environment and quality of road surfaces in the second climate zone [31].

3. The results of the research are consistent with the theory presented in $[5,6,12,13$, $17,19]$ and indicators of laboratory tests of physical and mechanical properties and structure of the binder.

\section{References}

1. I.A. Rybiev, Patterns in the structural and mechanical properties of asphalt concrete, Proceedings, VZISI, Moscow, (1957)

2. A.S. Kolbanovskaya, E. V. Mikhailov, Road bitumen (Publisher Transport, Moscow, 1973)

3. I.M. Rudenskaya, A.V. Rudensky, Organic binders for road construction, Publisher Transport, Moscow, (1984)

4. P. Morgan, A. Mulder, The Shell bitumen industrial handbook, Shell Bitumen, Surrey, (1995)

5. J. Read, D. Whiteoak, The shell bitumen handbook. Thomas Telford Ltd., London, (2003)

6. L. A. Girifalko, M. Hodak, R.S. Lee, Physical Rewiev, 62 (19), (2000)

7. A. E. Fals, V. G Hadjiev, F. C. Hernandez, Materials science and engineering, 558(13), (2012)

8. E. A. Skichko, at el., Fundamental research, 414(2), 3 (2012)

9. I. V. Sukhno, High-tech applications, 55, (2008) 
10. B.P. Tumanyan, Scientific and applied aspects of the theory of oil disperse systems (Publisher Technology, Moscow, 2000)

11. L.S. Quintero, L. E. Sanabria, Journal of Testing and Evaluation, 40 (7), (2012)

12. V.V. Yadykina et al., Innovative materials and technologies (XX research conference): International. Research-to-practice Conf., 11-12 Oct. Belgorod: proceedings, Belgorod, (2011)

13. S.Y. Shekhovtsova, Effective asphalt on the basis of nano-modified polymer-bitumen binde, Belgorod, (2016)

14. A.B. Solomentsev, Science and technology in the road sector, 14 (1) (2008)

15. V.Y. Dolmatov, Russian nanotechnology, 19 (7-8), 2 (2007)

16. E.V. Korolev et al., Construction materials, 76(4) (2012)

17. A. Saglik, Eurasian Eurobitume Congress, Istanbul, (2012)

18. E. M. Chernyshev et al. Construction materials, 32(2) (2008)

19. S. I. Wolfson et al., Bulletin of technological university, 29 (17) (2016)

20. R. V. Tarasov et al., Modern research and innovation, 5 (1) (2014)

21. R.A. Ibragimov, S.I. Pimenov, V.S. Izotov, Magazine of Civil Engineering, 54, 63-69 (2015), doi:10.5862/MCE.54.7

22. A.V. Denisov, Magazine of Civil Engineering 73, 70-87 (2017), doi:10.18720/MCE.73.7

23. R.A. Ibragimov, S.I. Pimenov, Magazine of Civil Engineering, 62, 3-12 (2016), doi:10.5862/MCE.62.1

24. A.R. Gaifullin, R.Z. Rakhimov, N.R. Rakhimova, Magazine of Civil Engineering, 59, 66-73 (2015), doi:10.5862/MCE.59.7

25. I.V. Susoeva, T.N. Vahnina, A.A. Titunin, J.A. Asatkina, Magazine of Civil Engineering, 71, 39-50 (2017), doi:10.18720/MCE.71.5

26. S.Y. Shekhovtsova, A.V. Korotkov, M.A. Vysotskaya, Magazine of Civil Engineering, 78, 91-100 (2018), doi:10.18720/MCE.78.7

27. L.V. Zakrevskaya, P.A. Lubin, S.N. Avdeev, I.A. Gandelsman, S.V. Filippov, Magazine of Civil Engineering, 75, 123-128 (2017), doi:10.18720/MCE.75.12

28. S.V. Klyuev, A.V. Klyuev, A.D. Abakarov, E.S. Shorstova, N.G. Gafarova, Magazine of Civil Engineering, 75, 66-75 (2017), doi:10.18720/MCE.75.6

29. D.A. Vakulenko, R.A. Turusov, Magazine of Civil Engineering, 75, 106-113 (2017), doi:10.18720/MCE.75.10

30. T.S. Shepelenko, N.P. Gorlenko, O.A. Zubkova, Magazine of Civil Engineering, 81, 125-134 (2018), doi:10.18720/MCE.81.13

31. L.V. Zakrevskaya, A.A. Gavrilenko, S.N. Avdeev, I.A. Gandelsman, A.V. Kireev, Magazine of Civil Engineering, 77, 121-129 (2018), doi:10.18720/MCE.77.11 